pulmonary oedema after intravenous use. The effects on the airways are less, being confined to users of marihuana or hashish who have short term bronchodilatation, ${ }^{3}$ although specific airways conductance may fall with long term use. ${ }^{4}$ The only report of asthma after opiate inhalation described three less severe cases managed in a casualty department, in which all three patients recovered without ventilation. ${ }^{5}$ Several studies have failed to show an increase in the incidence of asthma in opiate addicts, although in one study $28 \%$ of addicts with asthma had an attack within hours or days after using heroin. ${ }^{6}$ Most of the patients were intravenous drug abusers, and the incidence of asthma in addicts inhaling heroin is unknown.

The mechanisms provoking bronchoconstriction are probably multifactorial. Opiates are powerful releasers of histamine, which can produce bronchoconstriction and local oedema, especially in subjects with atopic allergy or asthma. ${ }^{7}$ Contamination with other drugs or talcs is probably less important when opiates are inhaled rather than injected. Inhaling freebase cocaine - that is, its alkaline derivative - can provoke reductions in the calibre of large and small airways greater than those from smoking tobacco alone. ${ }^{8}$ Central respiratory depression may also be important in depressing the normal compensatory respiratory responses to an asthmatic attack and so hasten the

onset of hypoxaemia and respiratory acidosis, thereby predisposing to early respiratory arrest. Early treatment with intravenous naloxone should help to reverse such central respiratory depression.

It is worrying that we failed to prevent recurrent and more severe attacks of asthma in our three patients despite recognition of their problem and appropriate counselling. The patients' reluctance to admit to their opiate addiction compounds the problem. The development of bronchospasm soon after inhaling heroin is a serious event and should be recognised as such.

1 Glassroth J, Adams GD, Schnoll S. The impact of substance abuse on the respiratory system. Chest 1987;91:596-613.

2 Madden JS. A guide to alcohol and drug dependence. Bristol: Wright, 1984.

3 Tashkin DP, Shapiro BJ, Frank IM. Acute effects of marihuana on airways dynamics in spontaneous and experimentally-induced bronchial asthma. In: dynamics in spontaneous and experimentally-induced bronchial asthma. In:
Craud MCB, Szara S, eds. The pharmacology of marihuana. New York: Raven Craud MCB, Szara S,

4 Tashkin DP, Calvarese BM, Simmons MS, Shapiro BJ. Respiratory status of seventy-four habitual marihuana smokers. Chest 1980;78:699-706.

5 Oliver RM. Bronchospasm and heroin inhalation. Lancet 1986; ; 915 .

6 Ghodse AH, Myles JS. Asthma in opiate addicts. F Psychosom Res 1987;31:41-4. 7 Jaffe JH, Martin WR. In: Gilman AG, Goodman LS, Gilman H, eds. The pharmacological basis of therapeutics. New York: MacMillan, 1980.

8 Tashkin DP, Simmons MS, Coulson AH, Clark VA, Gong H. Respiratory effects of cocaine "freebasing" among habitual users of marihuana with and without tobacco. Chest 1987;92:638-44.

9 British Thoracic Association. Death from asthma in two regions of England. BrMed F 1982;285:1251-5.

(Accepled 4 October 1988)

\title{
Diabetes in patients with hypertension receiving pharmacological treatment
}

\section{Hans Lundgren, Lars Björkman, Peter Keiding, Stefan Lundmark, Calle Bengtsson}

\begin{abstract}
Health Centre, Floda, Sweden

Hans Lundgren, MD, general practitioner
\end{abstract}

\section{Health Centre, Svenljunga, Sweden \\ Lars Björkman, MD, general \\ practitioner}

Health Centre, Dalsjöfors, Sweden

Peter Keiding, MD, general practitioner

Health Centre, Stavre, Trollhättan, Sweden Stefan Lundmark, MD, general practitioner

Department of Primary Health Care, Gothenburg University, Gothenburg, S-416 65 Sweden

Calle Bengtsson, MD, professor

Correspondence to: Dr Bengtsson.
We looked at the records of all patients attending four health centres who had coexisting hypertension and diabetes to find which of these conditions had been diagnosed first.

\section{Methods and results}

About $75-90 \%$ of patients with type II diabetes in our area of western Sweden are treated at health centres. We looked at the records of all patients attending our four health centres who had coexisting diabetes and arterial hypertension. The blood pressure of all diabetic patients had been recorded at least once a year, and the urine of all hypertensive patients had been examined for glucose: fasting blood glucose concentrations had been measured at least once a year in all hypertensive patients attending the health centre of Trollhättan, in a systematic sample of hypertensive patients in Floda, and when clinically indicated at the health centres in Dalsjöfors and Svenljunga.

\section{Results}

The table shows that of the 226 patients with coexisting arterial hypertension and diabetes, $183 \mathrm{had}$ had arterial hypertension before diabetes was diagnosed, while only 22 had had diabetes before hypertension was recognised; in all four health centres there was a significant overrepresentation of patients with hypertension developing diabetes compared with the opposite $(p<0.01$ for Floda, $p<0.001$ for the three other health centres and for the total series, $\chi^{2}$ test). All the 183 hypertensive patients whose hypertension had preceded diabetes had been taking antihypertensive drugs at the time of onset of their diabetes; all but four
Patients at four health centres in western Sweden with coexisting arterial hypertension and diabetes according to which condition developed first

\begin{tabular}{lccc}
\hline & $\begin{array}{c}\text { No who developed } \\
\text { hypertension } \\
\text { before diabetes }\end{array}$ & $\begin{array}{c}\text { No who had } \\
\text { diapertension and } \\
\text { same time }\end{array}$ & $\begin{array}{c}\text { No who developed } \\
\text { diabetes before } \\
\text { hypertension }\end{array}$ \\
\hline Floda & 23 & 4 & 2 \\
Dalsjöfors & 51 & 6 & 4 \\
Svenliunga & 55 & 7 & 10 \\
Trollhättan & 54 & 6 & 6 \\
\hline Total & 183 & 23 & 22 \\
\hline
\end{tabular}

had been taking a diuretic or a $\beta$ blocker, or both. The mean time between starting pharmacological treatment for hypertension and developing diabetes (about eight years) was similar for patients of the four health centres.

\section{Comment}

As hypertension is more common than diabetes it might be expected that a diabetic person would develop arterial hypertension. We found, however, that it was more common for a hypertensive patient to develop diabetes than for a diabetic to develop hypertension, and all the hypertensive patients were taking antihypertensive drugs at the time of onset of diabetes. This supports our previous finding that women who were taking antihypertensive drugs (diuretics or $\beta$ blockers, or both) had an increased risk of developing diabetes. ${ }^{22}$ Too few women in either of our studies were taking other antihypertensive drugs to allow us to drawn conclusions about the other drugs.

This is further evidence for a connection between antihypertensive drugs and risk of developing diabetes and is one more reason to consider nonpharmacological treatment for hypertension initially.

1 Bengtsson C, Blohmé G, Lapidus L, et al. Do antihypertensive drugs precipitate diabetes? Br Med f 1984;289:1495-7.

Bengtsson C, Blohme G, Lapidus L, Lundgren H. Diabetes in hypertensive women: an effect of antihypertensive drugs or the hypertensive state per se? Diabetic Medicine 1988;5:261-4.

(Accepted 26 August 1988) 